\title{
Study of indications of hysterectomy among benign gynaecology cases
}

\author{
Uma Pandey \\ Associate Professor, Dept. of Obstetrics and Gynaecology, Institute of Medical Sciences, Banaras Hindu University, Varanasi, \\ Uttar Pradesh, India
}

*Corresponding Author:

Email: uma.pandey2006@yahoo.com

\begin{abstract}
Objective: Prospective observational study of indications of hysterectomy and postoperative complications was done among benign gynaecology cases attending the outpatient department of Obstetrics and Gynaecology, Sir Sunder Lal Hospital, Banaras Hindu University, Varanasi, UP, India.

Materials and Methods: Those women attending the outpatient department of Obstetrics and Gynaecology, Sir Sunder Lal Hospital, Banaras Hindu University, Varanasi, UP, India who had hysterectomy done were given questionnaire to fill or member of health care team filled questionnaires on their behalf if they were illiterate. The study duration was from July 2011 to June 2016. We included only those patients in whom hysterectomy was done at less than 30 years of age and total abdominal hysterectomy was done. Patients were asked regarding indication of hysterectomy, their understanding of their illness, postoperative recovery and current problem.

Results: Total of 45 women gave information about their hysterectomy and their current health and they were all married. The 25-30 years age women were $93 \%$ in this observational study, $84 \%$ were from low socioeconomic status.

In our questionnaire survey $71 \%$ of cases of Total Abdominal Hysterectomy (TAH) was done for the complaint of vaginal discharge. These women disliked the wetness of their undergarments (even if mild); they thought it as a harbinger of some severe illness. Fibroid was second most common cause (15\%) in our group followed by heavy menstrual bleeding, then abdominal pain and prolapse.

The most important observation of this study is presenting complain of the patients in this study. It is remarkable that $71 \%$ of women were operated for persistent vaginal discharge, while in $51 \%$ it was persisting at the time of presentation. When they were examined they had physiological discharge from the vaginal wall. $8 \%$ patients had persistent granuloma, which was causing post coital bleeding and discharge, and was treated. $15 \%$ patients complained dyspareunia although no pathological cause could be elicited.

Last and the most important questions which was asked, whether women understood her illness? Why did she need operation? Was she told of the complications? Only $11 \%$ patients knew it (e.g. had fibroid). This is not surprising. Vaginal discharge and indication of hysterectomy was not discussed with them. They were probably not offered medical treatment. Whether it was due to ignorance or some other factor, we could not elicit.

Conclusion: This study shows higher rate of hysterectomy among patients with vaginal discharge. Majority of these women did not have medical treatment for their complain of vaginal discharge. Most important feature is that, in spite of hysterectomy these women continued to have vaginal discharge, which could perhaps indicates that their hysterectomies were unnecessary and their discharges were physiological. Education to health care workers and gynaecological patients is of utmost importance.
\end{abstract}

Keywords: Hysterectomy, Vaginal discharge, Indications of hysterectomy.

\section{Introduction}

Hysterectomy is the second most common gynaecological operation performed in the world, next to Caesarean section. ${ }^{1}$ The situation is same in India as well. Study done in Gujrat (western state of India) showed that $7-8 \%$ of rural and $5 \%$ of urban women had hysterectomy by the age they were 37 years. $^{2}$

Majority of the cases are indicated and genuine but there are certain cases in which patients or their relatives request for it as they have completed their family. Hysterectomy being the major operation is not without risks and complications. Therefore the indication for hysterectomy operation should be carefully evaluated and understood, both by surgeon and the patient. Informed consent and counseling is of prime importance.

The complication rates of hysterectomy operation vary from $0.5 \%-43 \%$ depending upon complexity of case chosen, gynaecologist' surgical expertise, premorbid condition of patient, blood bank and other logistical facilities.

It is also hypothesized that ovarian failure happens after hysterectomy (even when ovaries are preserved) due to decreased blood supply of ovary, approximately 3.7 years earlier along with all the consequences of premature menopause to the women. ${ }^{4}$

Complications of hysterectomy are infection, injury to ureter, injury to bowel, haemorrhage, psychological symptoms, urinary fistulas, vaginal vault prolapse, premature menopause and mortality related to complications. ${ }^{5,6}$

This study highlights the persisting morbidity among the women who underwent hysterectomy in peripheral hospital. Some were genuinely indicated and others were 'perhaps' not so indicated hysterectomy. There are also modern medical and conservative management options that have emerged which has 
reduced hysterectomy rate to a low level in the NHS, the United Kingdom.

In 1999-2000, half of the 51,858 hysterectomies performed in the public sector in England were for heavy menstrual loss. In contrast, 7179 hysterectomies were performed for heavy menstrual loss in 2004-5 while 9701 women underwent endometrial ablation over half of these (5457) by means of secondgeneration (non-hysteroscopic) techniques. ${ }^{7}$

Should we not educate our women more and counsel them regarding female body physiology and changes and illnesses. The Hippocratic oath is "primum nor nocere", first do no harm, all of us should take a pledge to support our women and not do unnecessary hysterectomy. ${ }^{8}$

\section{Materials and Methods}

Prospective observational study of indications of hysterectomy and postoperative complications was done among benign gynaecology cases attending the outpatient department of Obstetrics and Gynaecology, Sir Sunder Lal Hospital, Banaras Hindu University, Varanasi, UP, India.

Those women attending the outpatient department of Obstetrics and Gynaecology, Sir Sunder Lal Hospital, Banaras Hindu University, who had hysterectomy done somewhere else (from the catchment areas of Banaras Hindu University, a tertiary referral center hospital) were given questionnaire to fill or member of health care team filled questionnaires on their behalf if they were illiterate. The study duration was from July 2011 to June 2016. We included only those patients in whom hysterectomy was done at less than 30 years of age. Patients were asked regarding indication of hysterectomy, their understanding of their illness, postoperative recovery and their current problem. The cases we included were total abdominal hysterectomy.

\section{Results}

Hysterectomies were done in the other centers ie in the neighboring districts of Varanasi or in the state of Bihar, Jharkhand or Madhya Pradesh. But, after few months to years of hysterectomy, these patients had persisting symptoms/new symptom so they came to the Outpatient department of Sir Sunder Lal Hospital of Banaras Hindu University. When they reported to us we did the questionnaire survey. Some of them presented in the outpatient's 6 weeks after their operation while others 2-3 years later.

Total of 45 women gave information about their hysterectomy and their current health and they were all married. The 25-30 years age women were $93 \%$ in this observational study, $84 \%$ were from low socioeconomic status. $11 \%$ women had pre-existing diabetes and $2 \%$ had pre-existing hypertension (Table 1-3).
Table 1: Age

\begin{tabular}{|l|c|c|}
\hline & Total $=\mathbf{4 5}$ patients & Percentage \\
\hline 20-25 years & 3 & $6.66 \%$ \\
\hline 25-30 years & 42 & $93.33 \%$ \\
\hline
\end{tabular}

Table 2: Socioeconomic status

\begin{tabular}{|l|c|c|}
\hline & Total=45 patients & Percentage \\
\hline Low & 38 & $84.44 \%$ \\
\hline Middle & 7 & $15.55 \%$ \\
\hline Upper & 0 & $0 \%$ \\
\hline
\end{tabular}

Table 3: H/O Chronic illnesses

\begin{tabular}{|l|c|c|}
\hline & $\begin{array}{c}\text { Total=45 } \\
\text { patients }\end{array}$ & Percentage \\
\hline Type 1 Diabetes & 5 & $11 \%$ \\
\hline Hypertension & 1 & $2 \%$ \\
\hline
\end{tabular}

In our questionnaire survey $71 \%$ of cases of Total Abdominal Hysterectomy (TAH) was done for the complaint of vaginal discharge. These women disliked the wetness of their undergarments (even if mild); they thought it as a harbinger of some severe illness. Fibroid was second most common cause (15\%) in our group followed by heavy menstrual bleeding, then abdominal pain and prolapse (Table 4 ).

Table 4: Indications of Hysterectomy

\begin{tabular}{|l|c|c|}
\hline & $\begin{array}{c}\text { Total=45 } \\
\text { patients }\end{array}$ & Percentage \\
\hline $\begin{array}{l}\text { Vaginal } \\
\text { Discharge } \\
\text { (probable PID*) }\end{array}$ & 32 & $71 \%$ \\
\hline $\begin{array}{l}\text { Abdominal pain } \\
\text { (probable PID) }\end{array}$ & 2 & $4 \%$ \\
\hline HMB* & 3 & $6 \%$ \\
\hline Prolapse & 1 & $2 \%$ \\
\hline Fibroid & 7 & $15 \%$ \\
\hline
\end{tabular}

*Pelvic Inflammatory Diseases

**Heavy Menstrual Bleeding

Patients were specifically asked what complication did they have when they had operation in the peripheral hospital? Health care team members explained them regarding the questions before they answered their postoperative complications. $20 \%$ had wound infection, $15 \%$ Urinary tract infection, $11 \%$ had fever, $6 \%$ lung infection and $4 \%$ had mild bleeding. These complications were managed at the peripheral hospitals and patients improved (Table 5).

Table 5: Postoperative complications

\begin{tabular}{|l|c|c|}
\hline & $\begin{array}{c}\text { Total=45 } \\
\text { patients }\end{array}$ & Percentage \\
\hline Fever & 5 & $11 \%$ \\
\hline Bleeding & 2 & $4 \%$ \\
\hline Wound infection & 9 & $20 \%$ \\
\hline UTI $^{*}$ & 7 & $15 \%$ \\
\hline
\end{tabular}




\begin{tabular}{|l|l|l|}
\hline Lung infection & 3 & $6 \%$ \\
\hline Fistula & 0 & $0 \%$ \\
\hline
\end{tabular}

*Urinary Tract Infection

The most important observation of this study is presenting complain of the patients in this study. It is remarkable that $71 \%$ of women were operated for persistent vaginal discharge, while in $51 \%$ it was persisting at the time of presentation. When they were examined they had physiological discharge from the vaginal wall. $8 \%$ patients had persistent granuloma, which was causing post coital bleeding and discharge, and was treated. $15 \%$ patients complained dyspareunia although no pathological cause could be elicited. Abdominal pain and back pain was found in $11 \%$ patients respectively. Cause of abdominal pain was not obvious. $6 \%$ of patients had vasomotor symptoms and their FSH levels were in the menopausal range. 2\% (1patient) had vesico-vaginal fistula and she had that symptoms since the operation, but she reported to us 6 weeks after. This woman was managed in collaboration with Urological team of our teaching hospital. One woman reported with Vault prolapse but did not wish to have any surgical operation due to her personal situation (Table 6).

Table 6: Presenting complain

\begin{tabular}{|l|c|c|}
\hline & $\begin{array}{c}\text { Total=45 } \\
\text { patients }\end{array}$ & Percentage \\
\hline $\begin{array}{l}\text { Vaginal } \\
\text { discharge }\end{array}$ & 23 & $51 \%$ \\
\hline Dyspareunia & 7 & $15 \%$ \\
\hline Post coital bleed & 4 & $8 \%$ \\
\hline Prolapse & 1 & $2 \%$ \\
\hline Back pain & 5 & $11 \%$ \\
\hline $\begin{array}{l}\text { Menopausal } \\
\text { flushing }\end{array}$ & 3 & $6 \%$ \\
\hline Fistula & 1 & $2 \%$ \\
\hline Abdominal pain & 5 & $11 \%$ \\
\hline
\end{tabular}

Last and the most important questions which was asked, whether women understood her illness? Why did she need operation? Was she told of the complications? Only $11 \%$ patients knew it (e.g. had fibroid). This is not surprising. Vaginal discharge and indication of hysterectomy was not discussed with them. They were probably not offered medical treatment. Whether it was due to ignorance or some other factor, we could not elicit.

\section{Discussion}

A study by Wilcox et al reported that 35-44 years is the most common group for hysterectomy. ${ }^{9}$

Prevalence of complication was $15.5 \%$ in a study by Keerthana et al. Patients did not report any dyspareunia in their study. Our data collection is done in outpatients, so we are not able to compare it in exact terms. ${ }^{10}$

Women with premature menopause may suffer from night sweats, hot flushes, vaginal dryness, have psychological symptoms. These patients should be managed firstly with non-pharmacological treatments and if symptoms does not resolve pharmacological treatment should be started. They should be counseled regarding osteoporosis.

There should be a national guideline regarding management of benign pelvic conditions like pelvic inflammatory disease, heavy menstrual bleeding, prolapse uterus etc. These should be disseminated far and wide and strictly followed.

Limitation of this study is small sample size, done in outpatient; retrospective history and presenting complain were taken into account. It was the plight of these women that made me write this paper. My sincere hope that this will help our patients in some way.

\section{Conclusion}

This study shows higher rate of hysterectomy among patients with vaginal discharge. Majority of these women did not have medical treatment for their complain of vaginal discharge. Most important feature is that, in spite of hysterectomy these women continued to have vaginal discharge, which could perhaps indicates that their hysterectomies were unnecessary and their discharges were physiological. Health information should be given to doctors and patients regarding possible consequences of young age hysterectomy.

\section{Acknowledgment}

I would like to convey my sincere thanks to my patients who participated in this questionnaire survey.

\section{Conflict of Interest: None}

Funding: None

\section{References}

1. Wu JM, Wechter ME, Gellar EJ, Nguyen TV, Visco AG. Hysterectomy rates in the United States. Obstetrics \& Gynecology, 2007;110 (5):1091-95.

2. Desai S, Sinha T, Mahel A. Prevalence of hysterectomy among rural and urban women with or without health insurance in Gujrat, India. Reproductive health matters, 2011;19 (37):42-51.

3. Lee N, Dicker R, Rubin G, Ory H. Confirmation of preoperative diagnosis by hysterectomy. American Journal of Obstetrics \& Gynecology, 1984;150(3):283287.

4. Farquhar CM, Sadler L, Harvey SA, Stewart AW. The association of hysterectomy and menopause: a prospective cohort study. An International Journal of Obstetrics \& Gynecology, 2005;112 (7):956-962.

5. Davies A, Hart R, Magos A, Habad E, Morris R. Hysterectomy: surgical route and complications. Eur J Obstet Gynecol Reprod Biol. 2002;104:148-51. 
6. Maresh MJ, Metcalfe MA, McPherson K, et al. The VALUE national hysterectomy study: description of the patients and their surgery. BJOG 2002;109:302-312.

7. S Bhattacharya, LJ Middleton, A Tsourapas, AJ Lee, R Champaneria, JP Daniels, T Roberts, NH Hilken, P Barton, R Gray, KS Khan, P Chien, P O'Donovan, KG Cooper; The International Heavy Menstrual Bleeding Individual Patient Data Meta-analysis Collaborative Group. Hysterectomy, endometrial ablation and Mirena ${ }^{\circledR}$ for heavy menstrual bleeding: a systematic review of clinical effectiveness and cost-effectiveness analysis. NIHR Health Technology Assessment programme: Executive Summaries. 2011.

8. https://en.wikipedia.org/wiki/Hippocratic_Oath

9. CDC. Surgical sterilization surveillance: hysterectomy in women aged 15-44, 1970-1975. Atlanta: US Department of Health \& human Services, Public Health Service, CDC, 1980.

10. Radha K, Prameela GD, Chandrasekharan PA, Swathi P, Radha G, Keerthana. Epidemiology of Hysterectomy - A Cross Sectional Study among Piligrims of Tirumala. OSR Journal of Dental and Medical Sciences 2015; Volume 14, Issue $7 \mathrm{Pg}$ 01-05. 